\title{
POR QUE E COMO GRAMSCI FOI ASSASSINADO PELO FASCISMO
}

\author{
Ruggero Giacomini *
}

Resumo: O artigo discute as circunstâncias da morte de Antonio Gramsci abrindo uma investigação acerca da relação entre a hipótese de seu assassinato pelo fascismo italiano e a disputa político-cultural em torno de sua figura e sua obra teórica.

Palavras-chaves: Antonio Gramsci; Comunismo italiano; Fascismo.

\section{PERCHÉ E COME GRAMSCI FU ASSASSINATO DAL FASCISMO}

Riassunto: L'articolo tratta le circostanze della morte di Antonio Gramsci aprendo un'inchiesta sul rapporto tra l'ipotesi del suo omicidio dal fascismo italiano e la controversia politicoculturale sulla sua figura e sul suo lavoro teorico.

Parole-chiave: Antonio Gramsci; Comunismo italiano; Fascismo.

\section{WHY AND HOW GRAMSCI WAS KILLED BY THE FASCISM}

Abstract: This article discusses the circumstances of Antonio Gramsci's death by opening an investigation into the relationship between the hypothesis of his murder by the italian fascism and the political-cultural dispute over his figure and his theoretical work.

Keywords: Antonio Gramsci; Italian communism; Fascism.

\section{Oitenta anos da morte de Gramsci}

Antonio Gramsci morreu em 27 de abril de 1937, após ter sido por mais de dez anos prisioneiro do fascismo, submetido a torturas psicológicas e físicas e a sofrimentos inenarráveis, em meio aos quais, todavia, não havia nunca desistido de resistir e de lutar pela liberdade e o socialismo. Tinha 46 anos.

O fascismo o havia privado da liberdade quando em novembro de 1926, com a cumplicidade do rei Savoia, aboliu as garantias do Estatuto $^{1}$, livrando-se do Parlamento representativo. Buscou sistematicamente, a partir de então, com pressões e chantagens,

\footnotetext{
* Doutor em História dos Partidos e dos Movimentos Políticos. Diretor do Centro Cultural Marchigiano La Città Futura e Membro da Comissão Científica da Associazione Politico Culturale Marx XXI. Entre as obras que publicou estão Il Giudice e Il Prigioniero: Il carcere di Antonio Gramsci (Castelvecchi, 2014) e a biografia Antonio Gramsci (Teti, 1994). Foi também organizador, ao lado de Domenico Losurdo e Michele Martelli, do volume Gramsci e l'Italia (Istituto per gli Studi Filosofici, 1994). Este artigo foi publicado originalmente no site da Associazione Politico Culturale Marx XXI em 23 de abril de 2017. Tradução, resumos e notas explicativas de Marcos Aurélio da Silva, professor da UFSC.

${ }^{1}$ Referência ao Estatuto Albertino, o conjunto de regramento de matriz liberal do Reino do PiemonteSardenha, promulgado pelo rei Carlos Alberto em 1848, e que esteve na base da Constituição do Reino da Itália, quando da sua unificação como um Estado nacional no ano de 1861. Cf. Gramsci, A. Escritos Políticos. Vol. 1. Trad. C. N. Coutinho. Rio de Janeiro: Brasiliense, 204, p. 485.
} 
falsas informações e incessantes provocações, induzi-lo a pedir indulto, a capitular, a romper com os seus ideais e o seu partido. Não conseguiu. Foi nos seguintes termos que, da sua morte, deu burocraticamente a notícia dois dias depois um breve despacho da agência governamental Stefani: "Morreu na clínica privada Quisisana de Roma, onde estava hospitalizado há muito tempo, o ex-deputado comunista Gramsci”. A mesma nota foi transmitida pela rádio.

\section{O nome de Gramsci antes e depois da Liberação}

Durante mais de quinze anos, não se encontrou na Itália informações sobre Gramsci. Buscava-se fazer com que desaparecesse da memória. Os jovens ignoravam a sua existência. A recordação sobrevivia nos cárceres e nas ilhas de confinamento, entre os grupos comunistas e antifascistas na clandestinidade, nos trabalhadores mais velhos. No exterior a sua obra era ao contrário viva na imigração italiana, onde foi comemorado e chorado pelos comunistas italianos e pela Internacional, lembrado com respeito e honra pelos principais expoentes e jornais do antifascismo. Na luta partigiana, com o nome de Gramsci se intitulavam brigadas e destacamentos de assalto e, após a guerra, pelo exemplo político e moral que havia dado, torna-se ele o ponto de referência para aquela grande parte dos italianos que ansiava uma profunda renovação.

Começaram a ser publicados seus artigos do período em que era ativo politicamente e vieram a luz, graças ao empenho de Togliatti, os escritos carcerários. $\mathrm{O}$ "retorno" de Gramsci acompanhou a ação para afirmar o papel de classe e nacional do Partido Comunista Italiano e amalgamar no "partido novo", construído como força política homogênea, combativa e de massa, o afluxo de militantes saídos de experiências muito diversas: a clandestinidade, o cárcere e o confinamento, o exílio e o longo afastamento do país, o isolamento privado durante os anos sombrios, a experiência partigiana vivida por muitos jovens empurrados por um anseio de justiça, mas que pouco ou nada sabiam do marxismo, do comunismo e dos acontecimentos políticos anteriores ao fascismo.

Mas Gramsci não fora só descoberta de raízes. A sua figura e o seu pensamento se apoderaram como presença cultural forte na realidade nacional a partir das Cartas do Cárcere, avaliadas já desde o seu primeiro aparecimento em 1947 como uma obra prima de literatura, a qual de fato foi conferido o prêmio Viareggio. Seguiram-se os Cadernos 
do Cárcere, uma verdadeira descoberta pela sua riqueza e profundidade, publicados em volumes temáticos antológicos a partir de 1948, e depois várias vezes editados.

\section{Herança em disputa}

Desde o início, em torno da figura e da obra de Gramsci se abriu uma complexa disputa político-cultural, em cuja base estava o fato de que os adversários do Partido Comunista concluíam ser improvável e improdutivo um ataque frontal ao principal resistente e à principal vítima da luta contra o fascismo. Para estes adversários, já que se desenvolvia com diversidade de abordagens e interpretações um profícuo debate, útil ao conhecimento e à pesquisa, faziam-se necessárias simultaneamente operações voltadas a neutralizar e contrastar a sua herança.

Gramsci foi um revolucionário, o maior do século XX italiano e entre os maiores do mundo. Havia adquirido precocemente de Lenin a consciência de que a luta da classe operária não teria esperanças de sucesso sem a construção e a liderança de um partido revolucionário, o partido comunista. A esta tarefa prioritária ele havia dedicado a sua vida, antes e depois da prisão. Certamente Gramsci pode ser apreciado e compreendido também por quem não é marxista, não é comunista. Outra coisa, porém, são as distorções interessadas, as hipocrisias, as amputações dos seus ideais e da sua militância.

E foi exatamente este o ponto sobre o qual se mostraram ávidos e exercitaram-se das mais diferentes maneiras os adversários, buscando afogar na indefinição (un nulla indistinto) a sua obra. Trata-se de um ataque sob a forma do elogio, que seguiu e segue duas principais direções. A primeira, dos filósofos, é aquela da "monumentalização" do seu pensamento, a qual voltaram-se em parte também as instituições beneméritas que ao seu nome se reclamam - ou seja, apresentá-lo como a figura venerável de pensador fora do tempo e do espaço, a quem podem fazer referências indiferentemente políticos de direita e de esquerda. A segunda, dos "historiadores", trabalha especialmente sobre aspectos da biografia, não hesitando incorrer em evidentes falsificações, buscando

destacar Gramsci do Partido Comunista. É assim que o apresentam como um arrependido tardio do comunismo, às vezes livre e liberal, às vezes católico e socialista craxiano, adepto de "Justiça e Liberdade" e do Partido da Ação. E atualmente sustenta- 
se que tenha sido traído por seu partido, por Togliatti, sobretudo, mas também por Grieco $^{2}$ e por Longo ${ }^{3}$, postos, segundo a imaginação de quem escreve, sob as ordens de Stalin, ou por maldade própria.

Assim frequentado por uma destruidora publicística, o fascismo e Mussolini desaparecem como carcereiros e tiranos, sendo elevados a "protetores" e "benfeitores". Nada se fala sobre o tratamento desumano da tortura física e moral. São utilizados os receios de Gramsci sem se perguntar sobre a origem deles. Santifica-se a figura de um juiz instrutor militar a serviço do Tribunal especial, que era na verdade uma suspeita figura de provocador e um peão a mando do regime ${ }^{4}$. Nos interrogatórios sobre a morte, que muito provavelmente não foi natural, as perguntas são até mesmo invertidas nos interrogadores e nos interrogados, fantasiando-se acerca da irrupção na clínica de um grupo terrorista vindo do oriente. Sobre tudo isso me permito citar o meu Il giudice e Il prigioniero (2014).

\section{Uma coincidência suspeita}

Gramsci foi atingido por um derrame cerebral na noite de 25 de abril de 1937, ou seja, o mesmo dia em que o Tribunal havia confirmado o fim da sua pena e ele voltava à liberdade.

Conhecemos os desenvolvimentos deste dia graças a um relatório da cunhada Tania Schucht. Durante a manhã ela esteve nas dependências do Tribunal de Roma e havia retirado o livreto do juiz supervisor com a declaração de que o período da liberdade condicional se encerrara. Em consequência, as medidas de segurança, que no caso de Gramsci não haviam nunca cessado, deveriam chegar ao fim. Ele estava livre. Em 1934 Gramsci se encontrava na condição jurídica da "liberdade condicional", mas na realidade por disposição direta de Mussolini pesava sobre ele o mais estrito controle, vigiado noite e dia pela polícia e mantido prisioneiro. O seu propósito de hospitalizar-se para curar seu esgotamento em uma clínica para doentes nervosos aberta em Fiesole havia encontrado o não de Mussolini. E na clínica Quisisana em Roma uma esquadra de

\footnotetext{
${ }^{2}$ Ruggero Grieco (1893-1935), dirigente do PCI, membro da fração bordiguista em 1924, tendo depois aderido à linha de Gramsci, que dirige o partido desde 1925. Grieco foi o autor da polêmica carta enviada a Gramsci no cárcere em 1928. Na obra Il giudici e Il prigioniero Giacomini desvenda o papel interessado que teve o juiz Enrico Macis na interpretação que Gramsci tendeu a dar a epístola, considerando-a um ato conspirativo.

${ }^{3}$ Luigi Longo (1900-1980), secretário geral do PCI após a morte de Palmiro Togliatti, em 1964.

${ }^{4}$ Ver nota 2.
} 
policiais se alternava na entrada, enquanto agentes incógnitos se ocultavam em meio ao pessoal.

Quando Tania chegou à clínica por volta das $12 \mathrm{~h} 30$ com o documento do fim da pena, Gramsci estava bem, havia se alimentado e ela o deixou para que repousasse. Voltou próximo das $17 \mathrm{~h} 30$, discutiram acerca das novidades do dia, e depois procuraram palavras no dicionário "Larousse", uma vez que ela estava preparando uma lição privada de francês.

Depois - contou Tania - conversamos até a hora do jantar. À minha proposta de levar o livreto para que vissem lá embaixo, ou chamar o comissário, me disse que não havia pressa, que eu poderia fazê-lo outro dia. Jantou, como de hábito; provou a sopinha leve (minestrina), um pouco de fruta cozida e um pedacinho de pão de Espanha. E saiu, sendo transportado em uma cadeira levada por mais pessoas.

O dramático golpe ocorre, portanto, após o jantar, enquanto Gramsci se encontrava no banho. Aqui subitamente sentiu-se desmaiar. Caiu no chão agachando-se sem bater a cabeça. Com grande esforço se arrastou até a porta e pediu ajuda. Havia perdido o controle do lado esquerdo, mas, recorda Tania, “falava perfeitamente". Foi chamado um médico entre aqueles que se encontravam na clínica, o qual, segundo relatou ainda a cunhada

Não permitiu fazer qualquer injeção estimulante dizendo que esta não poderia senão piorar as condições, enquanto Nino com muito ímpeto pedia a injeção, um pedido de revigoramento, aliás, dizia para fazer uma dose dupla, ou seja, Nino estava perfeitamente em si, e com todas as particularidades contou ao doutor o que lhe aconteceu.

Antonio (Nino) estava, portanto, plenamente consciente, sublinha a cunhada. E pedia com insistência injeções e bebidas reanimadoras. Isso permite entender que ele suspeitasse que lhe tivessem feito ingerir substâncias venenosas e buscasse neutralizálas.

Por volta das $21 \mathrm{~h}$ daquela mesma noite chegou com seu assistente o diretor da clínica, professor Vittorio Puccinelli, que disse ter se atrasado em razão de uma operação de urgência. Gramsci contou também a ele o que lhe aconteceu. $\mathrm{O}$ médico havia recomendado gelo sobre a cabeça, um clister de sal e uma sangria que, porém, foram praticados com retardo, "após mais de uma hora", tempo em que havia vomitado 
muitas vezes e as condições haviam piorado. Apareceram então as freiras do hospital e chegou o padre, que aos veementes protestos de Tania para que deixasse o enfermo tranquilo, respondera "que não poderia fazê-lo". Se sentia provavelmente como o capelão de um cárcere mandado assistir a um condenado à morte. Na manhã seguinte veio para uma visita o professor Cesare Frugoni, chamado por Tania, que lhe havia pedido para colocar as sanguessugas nas mamas e fazer certas injeções. Mas o mesmo Frugoni estava desesperado, o desastre já havia ocorrido. Ocorreu de fato uma leve melhora na respiração durante a tarde, mas depois as condições se agravaram, e às 4 h10 do dia 27 de abril Gramsci parou de viver.

\section{Prisioneiro também após a morte}

Quando o irmão Carlo, que neste tempo foi avisado pelo telégrafo, chegou à clínica, o corpo de Antonio estava já na câmera mortuária e o ingresso vigiado e impedido pela polícia. Nesse tempo Tania havia telefonado a um amigo para que acompanhasse o formista que iria tirar a máscara facial, e a polícia havia pedido a ambos "várias declarações escritas", sobre a relação com a própria Tania, etc, etc. A prisão de Gramsci continuava severa mesmo após a morte. E é ainda Tania que se refere:

Depois vem o fotógrafo, e também ele teve a sua cota junto aos interrogadores. E quando a tarde voltou o irmão Carlo e se dirigiu diretamente à câmara mortuária para abri-la e foi interrompido, ao insistir na generalidade do ato, a proibição lhe foi confirmada dizendo-lhe que esta era a ordem do Ministério: que ninguém deveria ver o cadáver.

Carlo se irritou e o inspetor, não desdobrando provavelmente nem mesmo ele todo o procedimento, lhe consentiu passar, a ele e Tania, sempre, porém, "circundados de uma massa de agentes e de funcionários do Ministério do Interior”. A força pública esteve também "sempre presente em grande número", tanto no acompanhamento ao cemitério, quanto durante a cremação. A ordem do Ministério para não deixar ver o cadáver e o estrito controle até a cremação são pistas de uma consciência pouco límpida sobre a origem da morte, a respeito da qual não era permitido interrogar-se e indagar.

Foi um mérito de Tania ter mantido a lucidez naquelas dramáticas circunstâncias e ter conseguido, aproveitando a confusão, recolher e levar para fora da clínica os 
pertences pessoais de Gramsci e com eles os preciosos Cadernos, que pôs rapidamente aos cuidados da embaixada soviética onde trabalhava.

\section{Excusatio non petita}

Duas semanas após a morte de Gramsci, Il Messaggero voltava a ela com um breve e venenoso artigo em primeira página, que Tania julgou "uma verdadeira indecência" e a qual respondeu, de Paris, com uma campanha de cartas indignadas ao jornal romano. O artigo, publicado anônimo, era do próprio Mussolini, e Gramsci era arrolado entre "os mais insanos, fanáticos comunistas", aquele que "não era comparável realmente a nenhum".

Bastaria esta certificação de Mussolini, que era a confissão da falência de todos os esforços para induzi-lo a capitular, para liquidar como idiotices todas as fantasiosas teses sobre a sua pretensa conversão; até aquela do tal Lo Piparo a certificar-se com um fantasioso caderno "desaparecido", recuperável sempre que qualquer falsário a queira validar.

Mas no artigo de Mussolini havia também uma provocação e um despiste. Gramsci era apresentado como um seguidor de Trotsky que fugiu a tempo da Rússia e se abrigou na Itália, onde pôde "terminar os seus dias em uma ensolarada clínica de Roma”, encontrando "aquela paz que em outra parte é negada mesmo no limite da morte". Era urgente a Mussolini sublinhar com referências aos processos de Moscou que Gramsci morreu de morte natural e assim responder às suspeitas que entendia não deveriam circular.

A tese da morte natural não havia convencido o historiador Piero Melograni, desembarcado após uma peregrinação por diversas seitas políticas na praia do berlusconismo. A verdade é que ele oscilava fantasiosamente entre o suicídio e o mando staliniano, mas isso porque não levava em conta que Gramsci na clínica Quisisana era vigiado noite e dia pela polícia fascista e que só os fascistas podiam livremente aproximar-se dele e assassiná-lo. Em uma carta a Giulia (esposa de Gramsci - M. A. S.), de 6 de março de 1937, poucas semanas antes da tragédia, Tania escrevia a propósito:

É necessário que a polícia nos dê autorização para cada passo que queremos dar. Agora de Antonio se ocupa toda uma esquadra de agentes, não obstante por todo o tempo de sua estada aqui não tenha 
ele saído nem mesmo uma vez para ir ao jardim, (e) as suas condições de saúde sejam evidentes a todos.

Da mesma carta se percebe também a negligência do serviço de saúde da clínica com relação a ele e o descuido dos próprios médicos, em uma estrutura que era das mais renomadas e custosas da capital. Como se se soubesse que se ocupar daquele paciente especial pudesse ser comprometedor:

As condições da clínica, quanto à estrutura, tratamentos, refeições escrevia Tania -, deixam muito a desejar. E quanto ao perfil médico não apenas não temos um bom doutor ou doutores, mas em geral não temos nenhum doutor... Formalmente [Il prof. Puccinelli] é o médico que cuida de Gramsci, na realidade durante toda a permanência de Antonio na clínica passou no seu quarto não mais que cinco, seis vezes, e só para se informar como estava.

Deve-se notar que o médico da clínica, Vittorio Puccinelli, era irmão do médico pessoal de Mussolini, e que já nos meses sucessivos à prisão de Gramsci ele interviera sobre Tania, conhecida por seus estudos incompletos de medicina, advertindo, com “explícitas instruções”, quanto ao pedido de indulto. Ou seja, também ele um homem orgânico ao regime. Togliatti irá notar depois que os médicos eram comportados diante de Gramsci

Como se tivessem recebido a diretiva de deixá-lo morrer, pura e simplesmente. E esta diretiva eles haviam sem dúvida recebido para que nos últimos meses, enquanto as suas condições tornavam-se pouco a pouco mais graves, ele não fosse submetido a nenhuma visita, a nenhum cuidado, a nenhum tratamento de que tinha necessidade.

\section{A suspeita dos familiares e dos companheiros}

Que Gramsci tenha sido "ajudado" a morrer era precisamente a opinião da família. A cunhada Tania, próxima a ele nos últimos dias, estava convencida disso, como recordou a neta Olga, filha de Giuliano Gramsci:

Minha tia Tania não acreditava muito na versão oficial da morte que falava de uma hemorragia cerebral, retendo ser mais crivel a tese de um envenenamento.

Também Margarita Zacharova, primeira mulher divorciada de Giuliano Gramsci, procurada na Suécia por Giancarlo Lehner em busca de informações, lhe confirmou que "em família" se sustentava que tivesse sido envenenado. 
De fato, provocar uma hemorragia cerebral nas condições em que estava Gramsci não devia ser difícil. Bastaria simplesmente substituir um medicamento habitual por uma substância capaz de elevar subitamente a pressão arterial. A polícia secreta tinha livre movimentação na clínica, e dispunha de todas as possibilidades de fazê-lo. Algo do gênero ocorreria alguns anos depois nos cárceres da república para esconder as inconfessáveis relações com o chefe do bandido Salvatore Giuliano, Gaspare Pisciotta.

O doutor Raoul Bellok, um dos médicos da clínica Quisisana, recordou após a guerra:

Gramsci fora submetido a uma vigilância restritíssima por parte da polícia. Doze policiais foram distribuídos no jardim da Clínica, na Clínica mesma e fora do seu quarto. Certo dia também as freiras protestaram vivamente contra aquela implacável vigilância que representava um verdadeiro pesadelo para todos nós.

A vigilância mais insidiosa e muito perigosa era, porém, provavelmente aquela menos visível e documentável. Togliatti já no primeiro escrito em comemoração a Gramsci levantou a inquietante questão:

A morte dele permanece envolta em uma sombra que a torna inexplicável. À longa cadeia de torturas foi acrescido um último e inominável crime? Quem conhece Mussolini e o fascismo, sabe que avançar esta hipótese é legítimo. A sorte de Gramsci permanece inexplicável, sobretudo pelo momento em que ocorreu, quando a sua pena, reduzida por diversas medidas gerais de anistia e indulto, inspirava e lhe dava o direito de ser livre, de ter junto de si amigos $e$ médicos de confiança, para iniciar uma cura, para ser assistido.

A um ano da morte, o camarada Giovanni Parodi, operário turinês que havia dirigido a ocupação da Fiat em 1920, não tinha dúvida: Gramsci, que havia resistido firmemente às opressões infligidas por anos no cárcere da OVRA ${ }^{5}$, “deveria sucumbir seis dias após a data em que deveria ser liberado - a uma última mas eficaz poção." Parodi acreditava que Gramsci pudesse gozar seis dias ao menos de liberdade, enquanto na realidade, como vimos, não lhe foi concedida nem mesmo uma hora, nem mesmo depois de morto. É também revelador, na sua sucinta crueldade, um telegrama que na manhã de 26 de abril, às 10h45, o delegado de Roma, de nome Palma, enviou à primeira

\footnotetext{
${ }^{5}$ OVRA - Organização para a Vigilância e a Repressão do Antifascismo, a polícia política e secreta do
} regime de Mussolini. 
seção da Direção Geral dos Negócios Gerais e Reservados da PS (a Polícia do Estado M.A.S.), no qual falando erroneamente de "ataque cardíaco", informava, todavia, tão seguro de si: "Anuncia-se a morte". Se fosse uma hemorragia normal, o desfecho naquele momento não se poderia prever, porque mesmo privado das faculdades de movimento de uma parte do corpo, o paciente poderia igualmente sobreviver.

\section{A 'pistola fumegante'}

Certamente um leitor exigente pode sempre dizer que falta a prova da pistola fumegante, ou seja, a ordem escrita de Mussolini que comandava o crime. Mas uma ordem desse gênero não existe nem mesmo no caso dos irmãos Rosselli ${ }^{6}$ ou de Giacomo Matteotti ${ }^{7}$. "Estas são coisas - disse uma vez Mussolini ao secretário que o anotava que se faz a voz baixa”. E em uma nota do Diário de Ciano ${ }^{8}$ que tratava de antifascistas italianos capturados na Espanha, anarquistas e comunistas entre eles, pode-se ler: "Informo ao Duce que me ordena fuzilar todos, e acrescenta: os mortos não contam a história".

"Ninguém saberá nunca o nosso sofrimento", havia dito Gramsci ao irmão Gennaro que foi encontrá-lo no cárcere de Turi. E de fato ele foi impedido de poder contá-lo. Foi quase certamente a liberação condicional concedida juridicamente por Mussolini a Gramsci por razões de imagem internacional - em geral considerada como uma medida humanitária em favor do líder do PCI -, que o levou a decretar a sentença de morte. O regime de fato não pretendia de modo algum correr o risco de tê-lo livre.

De resto, também assim ocorreu com outros máximos dirigentes comunistas. Basta citar o caso de Umberto Terracini. Processado junto com Gramsci e condenado a uma longa pena prisional, termina de cumpri-la em 19 de fevereiro de 1937. Deveria estar livre, mas foi retido no cárcere por disposição ministerial, até que no dia 5 de abril do mesmo ano, por ordem da Comissão provincial, lhe foram impostos outros 5 anos de

\footnotetext{
${ }^{6}$ Carlo Rosselli (1899-1937) foi um dos líderes do antifascismo italiano. Exilado na França, foi um dos fundadores do movimento liberal-socialista Giustizia e liberta (1929), tendo também participado da guerra civil espanhola no ano de 1936, onde liderou um grupo de voluntários. Em junho de 1937 ele e o irmão Nello Rosselli foram assassinados na Normandia por terroristas franceses de extrema-direita. Ver Gramsci, A. Cartas do Cárcere. Vol. 1 Trad. L. S. Henriques. Rio de Janeiro: Civilização brasileira, 2005, p. 169.

${ }^{7}$ Deputado socialista assassinado pelo fascismo em 10 de junho de 1924 após ter pronunciado na Câmara um duro discurso contra o governo fascista. Ver Gramsci, A. Escritos políticos - 1921-1926. Vol. 2. Trad. C. N. Coutinho. Rio de Janeiro: Civilização brasileira, 2004, p. 16.

${ }^{8}$ Referência a Gian Galeazzo Ciano, genro de Mussolini e ministro de Assuntos Exteriores da Itália fascista entre 1936 e 1943.
} 
confinamento. Quando depois terminou de cumpri-los, em 19 de fevereiro de 1942, foi condenado novamente a outros cinco. E de cinco em cinco teria morrido prisioneiro, se o fascismo não tivesse caído. Para Gramsci a liberação condicional excluía a data limite em que lhe poderia ser imposto um novo período restritivo. O fascismo resolveu a dificuldade a sua maneira. 